\title{
ESMAT
ESM
}

15

\section{POLÍTICA DE DROGAS E O PRINCÍPIO DA INTERVENÇÃO MÍNIMA: ASPECTOS SOCIAIS E DIREITOS HUMANOS}

DRUG POLICY AND THE PRINCIPLE OF MINIMUM INTERVENTION: SOCIAL ASPECTS

AND HUMAN RIGHTS

Oneide Perius

Doutor em Filosofia. Professor do curso de Filosofia da UFT e do Mestrado em Prestação Jurisdicional e Direitos Humanos - UTF/ESMAT.

William Trigilio da Silva

Mestre em Prestação Jurisdicional e Direitos Humanos no Programa de Mestrado em Prestação Jurisdicional e Direitos Humanos - UFT/ESMAT. Juiz de Direito.

\section{RESUMO}

Este artigo pretende mostrar, com base numa coleta de dados feita na comarca de Paraíso do Tocantins/TO, como o direito penal e atual política de drogas no Brasil contribuem no processo de segregação e etiquetamento de determinada classe social. Desde os princípios da intervenção mínima e dos direitos humanos, pretendemos propor outra leitura do papel do direito penal em nossa sociedade e uma necessária reconsideração das bases da atual política de drogas no Brasil.

PALAVRAS-CHAVE: Direito Penal; Direitos Humanos; Política de Drogas; Labeling Approach; Intervenção Minima.

\section{ABSTRACT}

This article aims to show, based on a data collection made in Paraíso do Tocantins -TO, how the criminal law and current drug policy in Brazil contribute to the process of segregation and labeling of a certain social class. From the principles of minimum intervention and human rights, we intend to propose another reading of the role of criminal law in our society and a necessary reconsideration of the basis of current drug policy in Brazil.

KEYWORDS: Criminal Law; Human Rights. Drug Policy; Labeling Approach; Minimum Intervention. 


\section{INTRODUÇÃO}

A crescente presença das drogas ilícitas em nossa sociedade é imediatamente atestada por qualquer observador que se debruce sobre esse fenômeno. Sua presença alcança as mais variadas classes sociais e faixas etárias, até mesmo adolescentes e crianças, de tal modo que atualmente é considerada uma verdadeira patologia social. $\bigcirc$ problema está em toda parte e diariamente vemos esforços e planos serem divulgados para um tratamento mais eficaz da questão. $\bigcirc$ poder público precisa se manifestar, e a sociedade cobra ações efetivas em relação a esse problema. Ao que parece, no entanto, as ações do Estado no seu enfrentamento não estão, por ora, alcançando grande sucesso. Pretendemos, ao longo deste artigo, apresentar argumentos para demonstrar, por um lado, a ineficiência da atual política de drogas e, por outro, a necessidade de repensar suas bases.

Como intencionamos ressaltar, o princípio da intervenção mínima, pautado no respeito aos direitos humanos, deverá ser o ponto de partida e o ponto de chegada de qualquer modelo de enfrentamento do problema de drogas. Pretendemos, assim, lançar luz sobre a opacidade do discurso punitivista de que quanto mais repressão (que tem um altíssimo custo para o Estado e para a sociedade) menos problemas com drogas. $\bigcirc$ que se verifica, cada vez mais, é que o público-alvo dessa repressão é, em sua maioria, composto por usuários e pequenos distribuidores que, em sua vulnerabilidade, não conseguem se esquivar do poder repressor.

Este artigo, para cumprir a exigência científica de uma argumentação consistente, parte de uma análise de dados coletados na comarca de Paraíso do Tocantins. Pretendemos evidenciar, com base nesses dados, como na prática se traduz o modelo penal punitivista. A análise nos permitirá demonstrar que a política de drogas se converte em um avatar de criminalização de uma classe e etiquetamento de grupos sociais e pessoas em situação de vulnerabilidade. A partir desse diagnóstico, propomos, neste artigo, alternativas a esse modelo. $\bigcirc$ amplo escopo de debates contemporâneos sobre direitos humanos será a base de apoio para a busca de propostas alternativas.

\section{A POLÍTICA DE DROGAS E O PRINCÍPIO DA INTERVENÇÃO MÍNIMA}

Ao longo da história moldou-se um estereótipo de que o traficante é o mal que precisa ser combatido, como forma de diminuir a criminalidade, já que grande parte dos crimes está, direta ou indiretamente, relacionada ao tráfico. Esse tem sido o argumento que serve como recurso de justificação para a defesa do atual modelo de combate ao tráfico. Contudo, uma análise mais aprofundada do tema, tendo como referencial teórico as diretrizes da teoria da reação social ou labeling approach (Howard Becker, Erving Goffman), revela que o tratamento dado ao problema do tráfico de drogas necessita ser abordado desde paradigmas que não se restrinjam ao aspecto criminal. Pela teoria da reação social, que se propõe a explicar o processo de criminalização, as definições de delito são influenciadas por questões político-sociais que orientam o 
sistema penal acerca dos comportamentos socialmente adequados, permitindo a discriminação das condutas que não se conformam com o padrão imposto. Assim, a referida teoria nos faz suspeitar de que o sistema penal estaria incumbido de definir os comportamentos desviantes e reagir contra esses desvios.

A teoria da reação social evidencia que a identificação do delinquente não é feita levando-se em conta apenas o comportamento desviante. $\bigcirc$ criminoso é identificado após ação das instâncias oficiais (polícia, ministério público, juízes) que, ao atuarem, etiquetam as pessoas, criando o status de delinquente, já que muitos, embora pratiquem comportamentos inadequados, acabam não sendo etiquetados. Nesse passo, o sistema penal teria a função de definir a ação reprovada e o respectivo transgressor que só alcançaria essa condição após receber a etiqueta do próprio sistema.

A definição do que seria uma conduta desviada, por sua vez, passa por duas etapas. A criminalização primária que é feita pelo poder legislativo, ao definir a ação ou omissão como crime, e a criminalização secundária, que é exercida pelo sistema penal (polícia, ministério público e judiciário). Na segunda etapa da criminalização, em razão da abrangência das figuras típicas criadas e da falta de estrutura, a polícia escolhe aqueles que irão responder pelos desvios. Normalmente o foco recai sobre os indivíduos estereotipados, selecionados pelo sistema para responderem por esses desvios. Basta perceber que o trabalho ostensivo da polícia, no caso do tráfico de drogas, se concentra nos bairros pobres, becos e favelas onde se pressupõe que o crime se desenvolve. E o direcionamento das ações voltadas a punir os desvios apenas de uma classe marginalizada, no caso do tráfico, acaba por definir duas categorias econômicas na exploração do ilícito. A primeira, composta por pequenos "comerciantes" integrada pelos "aviãozinhos", "mulas", cuja atividade se esgota no mero propósito de subsistência ou simplesmente manutenção do vício, e os "grandes comerciantes", que acumulam fortuna por meio do mercado ilícito.

Assim, o sistema penal interfere no mercado negro e fomenta o crescimento da renda do proibido, protegendo aqueles que realmente lucram e conseguem converter o negócio ilícito em lícito, por meio da lavagem de dinheiro, e exclui do mercado o "comerciante" mais vulnerável. Basta ver o perfil dos condenados por tráfico. Se o tráfico é realmente uma atividade lucrativa, por que raramente encontramos traficantes ricos presos? A pequena quantidade de traficantes ricos presos não se justifica pela ausência do exercício da atividade ilegal desse tipo de pessoa, mas sim porque o sistema penal não os seleciona para responder pelo ilícito.

Nesse sentido, o levantamento Nacional de Informações Penitenciárias (INFOPEN), dezembro de 2014, apresenta dados os quais demonstram que, das 622.202 pessoas em situação de privação de liberdade (homens e mulheres), 28\% ( 174.216 presos) estão presas por força de condenações decorrentes da aplicação da Lei de Drogas. Esse porcentual, se analisado sob a perspectiva do recorte de gênero, revela uma realidade ainda mais brutal: $64 \%$ das mulheres em situação de privação de liberdade estão envolvidas com os tipos penais de tráfico de entorpecentes ou associação para o tráfico. 
Muitos desses reflexos podem ser observados a partir do levantamento de dados de processos por tráfico de drogas condenados em primeiro grau, entre os anos de 2012 e 2015 na comarca de Paraíso do Tocantins/TO. Seguem dados que podem nos auxiliar em uma análise mais ampla e criteriosa do problema.

No que se refere à idade dos apenados, a pesquisa revelou o que segue:

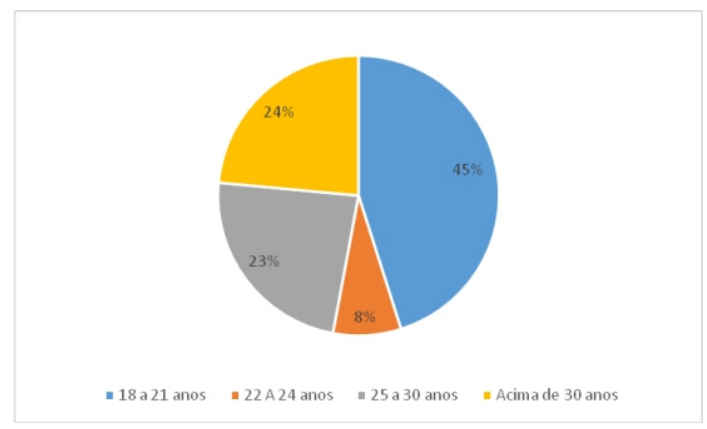

Gráfico I : Idade dos Réus - Drogas

Fonte: Pesquisa acadêmica (20 | 6)

Pelo levantamento, percebe-se que os apenados são na maioria jovens, já que $45 \%$ possuem entre I 8 e 2 I anos; $8 \%$ entre 22 e 24 anos; e 23\% entre 25 e 30 anos. Apenas $24 \%$ possuem acima de 30 anos. Por sua vez, no que tange à escolaridade, obtiveramse os seguintes resultados:

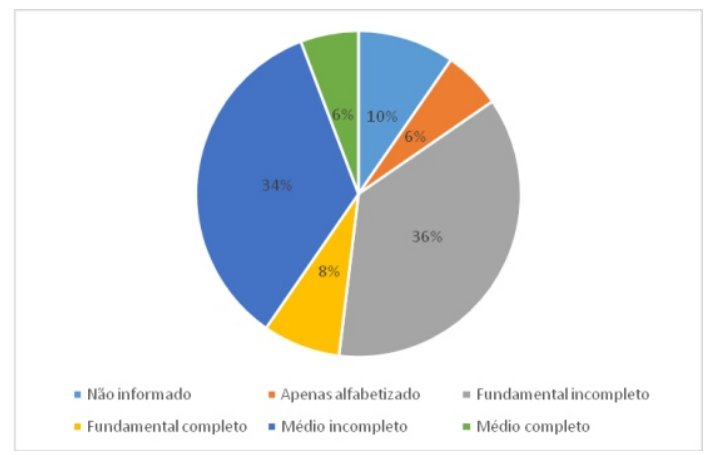

Gráfico 2: Escolaridade-Réus-Drogas

Fonte: Pesquisa acadêmica (20 | 6)

A pesquisa revelou que os apenados, em regra, são pessoas analfabetas ou com baixo nível de escolaridade. $10 \%$ não informaram a escolaridade; $6 \%$ declararam ser apenas alfabetizados; $36 \%$ declararam ter nível fundamental incompleto; $8 \%$ 
declararam ter ensino fundamental completo; $34 \%$ declararam ter ensino médio incompleto; e $6 \%$ declararam ter ensino médio completo. Nenhum possui nível superior.

No que se refere à renda mensal, obteve-se a seguinte resposta:

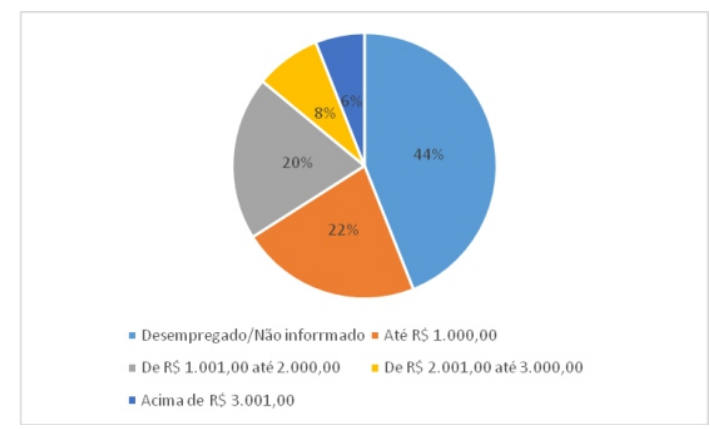

Gráfico 3: Renda Mensal - Réu -Drogas

Fonte: Pesquisa acadêmica (20 |6)

Assim, percebe-se que entre os apenados a renda também é baixa. $44 \%$ não informaram a renda ou declararam estar desempregados; $22 \%$ declararam ganhar até $\mathrm{R} \$ 1.000,00 ; 20 \%$ afirmaram ganhar de $\mathrm{R} \$ 1.001,00$ até 2.000,00; $8 \%$ declararam ganhar entre $R \$ 2.001,00$ e $R \$ 3.000,00$; e $6 \%$ declararam ganhar acima de $R \$$ $3.001,00$.

No que diz respeito à quantidade de droga apreendida, observou-se que a maior parte diz respeito à maconha, crack e cocaína, nas seguintes proporções:

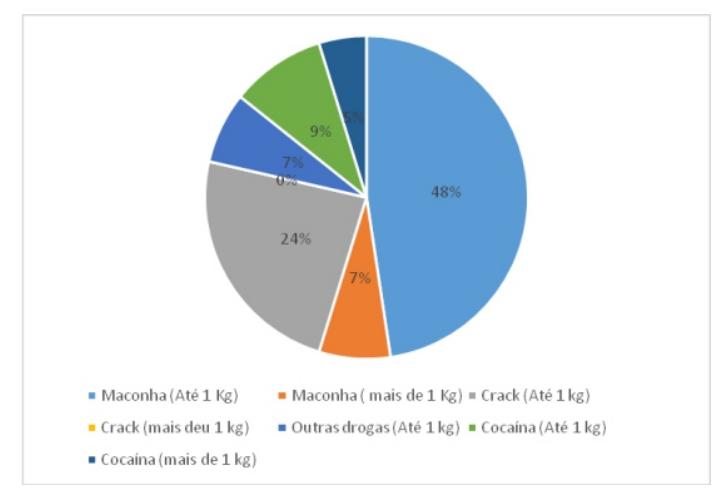

Gráfico 4: Quantidade de Droga Apreendida.

Fonte: Pesquisa acadêmica (20 |6) 
Verifica-se que $48 \%$ dos apenados foram identificados com menos de $1 \mathrm{~kg}$ de maconha; e 7\%, com mais de $1 \mathrm{~kg}$. Assim, das drogas apreendidas, 55\% diz respeito à maconha. Doutro lado, $24 \%$ foram identificados com menos de $1 \mathrm{~kg}$ de crack; $0 \%$ com mais de I kg de crack; 9\% foram identificados com até I kg de cocaína; e 5\% com mais de 1 kg de cocaína. Por fim, 7\% dos condenados estavam traficando outras drogas.

Portanto, a pesquisa revela que o perfil dos apenados por tráfico de drogas é de jovens que possuem pouco estudo e baixa renda mensal, e são presos com pouca quantidade de drogas, na maioria dos casos maconha.

Assim, o atual sistema contribui com a marginalização de uma camada social específica, porque, de acordo com a teoria da reação social, o sistema penal acaba por selecionar as condutas proibidas e as pessoas que irão responder pelos respectivos desvios, fazendo com que a ação estatal de combate e repressão se volte apenas para um grupo ou camada social estereotipada, normalmente formada por pobres, com baixo nível de instrução, que acabam sendo afastados do mercado lícito de trabalho e absorvidos pelo mercado ilícito.

Paralelamente, esses "traficantes" (pequenos mercadores), superlotam os presídios e contribuem com a falência do sistema prisional. Mas, do ponto de vista do sistema atual, "justificam" os milhões de gastos com as políticas voltadas à repressão do mercado ilícito, já que boa parcela de outros crimes também é atribuída ao tráfico.

Nesse contexto, percebe-se que, a despeito de as políticas de regulação e proibição se apoiarem na bandeira da "proteção à saúde pública", historicamente o mercado das drogas sempre foi regulado a partir de escusos interesses econômicos e serve como instrumento de controle sobre determinados seguimentos sociais. Não é por acaso que várias outras substâncias que poderiam ser incluídas no conceito de drogas, em razão dos efeitos deletérios que causam à saúde, não foram selecionadas como proibidas, a exemplo do tabaco e do álcool.

No que concerne ao tratamento das drogas, em muitas oportunidades, verifica-se que o Direito Penal ofende o princípio constitucional da igualdade, porque confere tratamento idêntico aos "pequenos" e aos "grandes" traficantes. Da mesma forma, por vezes, agride o princípio da dignidade da pessoa humana quando, ao estigmatizar uma classe social e não the oferecer condições mínimas, favorece a sua inclusão no sistema penal e contribui com a marginalização social, com consequências irreversíveis.

Ademais, o Direito Penal tem violado o princípio constitucional da intervenção mínima, uma vez que está sendo utilizado como forma de resolução de conflito social antes mesmo de esgotados outros meios de pacificação. Assim o fazendo, não atende aos postulados do Estado Democrático de Direito, que, por sua vez, não atua como objeto limitador do poder punitivo estatal capaz de proteger o cidadão contra os arbítrios do poder de polícia do Estado.

No entanto, se o sistema penal serve como instrumento das classes dominantes para manter sua hegemonia, então qual seria a solução? Parece muito simples a ideia de abolir o sistema penal, como sustentam as correntes abolicionistas, já que essa solução implicaria radical modificação da própria estrutura de poder construída ao longo da 
história. Também não existe um modelo pronto que possa ser sugerido para substituição do sistema penal. Dessa forma, segundo Zaffaroni e Pierangeli (200 I, p. 77), o que não nos parece bom poderia piorar:

A proposta socialista radical conduziria a política criminal a um abolicionismo total, pois nada seria possível fazer-se até que se operasse uma mudança total na estrutura do poder. A proposta ecológica importaria no risco de, uma vez suprimido o sistema penal, o lugar deste vir a ser ocupado por formas de controle social ainda mias repressivas e irracionais (controle psiquiátrico, administrativo, etc.). Essas propostas máximas radicais absolutas possuem, pois, o risco de que fala o velho adágio: "O melhor pode ser inimigo do bom". Nesse caso, o adágio pode ser ajustado para a seguinte expressão: "O bom pode se tornar pior do que o mau".

Nessa perspectiva, considerando que as sociedades são marcadas pela luta das classes dominantes em manter sua hegemonia, e que o sistema penal acaba sendo utilizado para viabilizar a marginalização das classes dominadas, Zaffaroni e Pierangeli (200I, p. 78) propõem a elaboração de uma política criminal alternativa capaz de racionalizar e limitar o poder punitivo, que denominam princípio da intervenção mínima:

Ante a constatação de que em uma sociedade existe o fenômeno dual "hegemonia-marginalização", e que o sistema penal tende, geralmente, a torná-lo mais agudo, impõe-se buscar uma aplicação das soluções punitivas da maneira mais limitada possível. Igualmente, a constatação de que a solução punitiva sempre importa num grau considerável de violência, ou seja, de irracionalidade, além da limitação de seu uso, impõe-se, na hipótese em que se deva lançar mão dela, a redução, ao mínimo, dos níveis de sua irracionalidade. Esta linha de limitação da intervenção punitiva e redução da irracionalidade (ou violência) da mesma, é o que se denomina princípio da intervenção mínima.

Pelo princípio da intervenção mínima o Direito Penal deve se ocupar da proteção dos bens mais relevantes para a sociedade, cuja proteção se mostra insuficiente pelos demais ramos do direito. Daí o porquê de também ser chamado de ultima ratio. Além disso, o princípio da intervenção mínima deve orientar o legislador no papel de descriminalizar condutas outrora reconhecidas como graves, mas que perderam a gravidade em função das mudanças de paradigmas da sociedade, ou em razão da demonstração de que as referidas condutas podem ser tuteladas por outro ramo da ciência jurídica. É o que enfatiza Rogério Greco (201 5, p. 99): 


\begin{abstract}
As vertentes do princípio da intervenção mínima são, portanto, como que duas faces de uma mesma moeda. De um lado, orientando o legislador na seleção dos bens mais importantes e necessários ao convício em sociedade; de outro, também servindo de norte ao legislador para retirar a proteção do Direito Penal sobre aqueles bens, que no passado gozavam de especial importância, mas que hoje, com a evolução da sociedade, já podem ser satisfatoriamente protegidos pelos demais ramos do ordenamento jurídico.
\end{abstract}

Assim, o princípio da intervenção mínima está a serviço do Estado Democrático de Direito, porque visa liminar o poder punitivo estatal e garantir a mínima interferência do Direito Penal nas relações sociais e a sua moderada aplicação quando o sistema punitivo se mostra necessário ao controle dos desvios.

Faz-se necessária, desse modo, uma mudança de paradigma. Nessa perspectiva, o direito penal, que desempenha papel limitador do poder punitivo estatal dentro do Estado de Direito, só pode ser utilizado como ultima ratio. Fora disso, servirá como instrumento de segregação social. A política de drogas deve ser redimensionada para que os investimentos sejam concentrados na prevenção e no tratamento de dependentes, relegando a segundo plano o combate e a repressão, já que esse modelo tem apenas contribuído com a valorização do ilícito, e com estigmatização de determinados seguimentos sociais.

\title{
3 DIREITO PENAL E DIREITOS HUMANOS
}

Nessa nova estrutura, portanto, o direito penal ocupa papel de destaque e se apresenta como viga de sustentação, porque tem a função de limitar o poder punitivo estatal e assegurar que o próprio Estado se oriente pelos preceitos constitucionais que asseguram os direitos e garantias fundamentais. Contraponto do Estado de Direito é o Estado de Polícia que prioriza os interesses do Estado, sem se comprometer em assegurar as garantias e liberdades individuais dos cidadãos.

Assim, na perspectiva do Estado de Direito, quando há um tencionado pelo Estado de Polícia, que se caracteriza pelos excessos punitivos, o Direito Penal age de forma a limitar esse poder de punição, com o propósito de salvaguardar as garantias e liberdades individuais e manter incólume a própria estrutura do Estado de Direito. Sobre o assunto, Zaffaroni (2007, p. 173) assevera:

O direito penal de um Estado de direito, por conseguinte, não pode deixar de esforçar-se em manter e aperfeiçoar as garantias dos cidadãos como limites redutores das pulsões do Estado de polícia, sob pena de perder sua essência e seu conteúdo. Agindo de outro modo, passaria a liberar poder punitivo irresponsavelmente e contribuiria para aniquilar o Estado de 
direito, isto é, se erigiria em ramificação cancerosa do Estado de direito.

E mesmo nos contornos do Estado de Direito, como o exercício do poder punitivo estatal, via de regra, tem o objetivo de suprimir direitos fundamentais, entre os quais a liberdade. $\bigcirc$ Direito Penal deve ser entendido como ultima ratio, isto é, deve ser o último recurso que o legislador deve se valer para assegurar a obediência ao padrão de comportamento socialmente aceito, haja vista as consequências de uma condenação criminal. Se utilizado de forma arbitrária, fora das diretrizes constitucionais que justificam a sua intervenção, pode se tornar uma perigosa arma violadora dos direitos humanos.

Ao longo dos anos, a política de regulação/proibição de algumas drogas, a pretexto de proteger o bem jurídico (saúde pública), tem gerado verdadeira guerra civil, com números assustadores de óbitos, cujas mortes estão relacionadas ao confronto direto entre policiais e traficantes, à disputa de territórios entre traficantes, à custa da manutenção do alto índice de adimplência do negócio ilícito que, ante sua clandestinidade, é assegurado por meio da violência, e ainda os decorrentes de latrocínios promovidos por usuários para sustentar o vício.

Enquanto isso, o próprio sistema penal, por excluir apenas os concorrentes menores, acaba por proteger os verdadeiros beneficiários do mercado das drogas, aqueles que movimentam o bilionário mercado, conseguem converter os lucros ilícitos em negócios lícitos e, em razão do poder financeiro que ostentam, exercem forte influência na definição das condutas proibidas e das pessoas que irão responder por elas. Por integrar ou se aproximar da cúpula do poder, ditam as regras sociais e, por óbvio, advogam a favor dos seus interesses para que estas jamais os prejudiquem.

\section{CONSIDERAÇÕES FINAIS}

Nestas considerações finais se faz necessário recapitular o caminho lógico-teórico percorrido para se chegar às conclusões explicitadas no presente estudo, forjado nas seguintes ponderações: a) Observou-se que, ao longo dos anos, tem se adotado uma política de regulação/proibição de algumas drogas que, a pretexto de proteger o bem jurídico (saúde pública), tem gerado verdadeira guerra civil, com números assustadores de óbitos relacionados à disputa de territórios entre traficantes, à custa da manutenção do alto índice de adimplência do negócio ilícito que, como se sabe, é garantido com o emprego de violência, e no combate/repressão ao comércio ilegal; b) Notou-se também que essa política tem contribuído para marginalizar camadas sociais, porque, de acordo com a teoria da reação social, o sistema penal acaba por selecionar as condutas proibidas e as pessoas que irão responder pelos respectivos desvios, fazendo com que a ação estatal de combate e repressão se volte apenas para um grupo ou camada social estereotipada, normalmente formada por pobres, com baixo nível de instrução, que acabam sendo afastados do mercado lícito de trabalho e absorvidos pelo mercado ilícito; c) $\bigcirc$ próprio sistema penal, por excluir apenas os concorrentes menores, acaba por 
proteger os verdadeiros beneficiários do comércio das drogas, aqueles que movimentam o bilionário mercado, conseguem converter os lucros ilícitos em negócios lícitos e, em razão do poder financeiro que ostentam, exercem forte influência na definição das condutas proibidas e das pessoas que irão responder por elas, criando, assim, um círculo cruel e vicioso; d) Consequência disso é que esses "traficantes" (pequenos mercadores) superlotam as penitenciárias e cadeias públicas e contribuem com a falência do sistema prisional. $\bigcirc$ endurecimento da legislação de combate às Drogas (Lei n⿳ I I.343, de 2006), que elevou substancialmente o encarceramento por crimes relacionados às drogas, quando confrontada com a ausência de diminuição do comércio ilícito e com o aumento de usuários, revela claramente que a política de repressão não tem se mostrado eficaz e sinaliza que os investimentos prioritariamente devem estar voltados à educação, prevenção e tratamento dos viciados, deixando a repressão em segundo plano.

Ante as ponderações acima, faz-se necessário observar que a maioria dos "pequenos comerciantes" é fruto da ausência de investimento em áreas básicas de saúde, educação, esporte e lazer, capaz de oportunizar sobrevivência por meios dignos. Distante do mercado formal, essas pessoas são atraídas pelo mercado ilícito e, sozinhas, pagam a conta dos inúmeros crimes relacionados ao tráfico. Não é por acaso que o perfil dos presos por tráfico de drogas é de pessoa pobre, os quais moram na periferia das cidades, não têm curso superior e, normalmente, estão desempregados. Isso não significa que o tráfico não seja realizado por pessoas mais abastadas, mas o sistema penal não os seleciona para responder pelo ilícito. A análise estatística feita numa comarca do estado do Tocantins, para este estudo, confirmou esse argumento. $\bigcirc$ encarceramento de pessoas com esse perfil, longe de resolver o problema, tem onerado os cofres públicos, além de carimbar a passagem do condenado para o mundo crime, já que praticamente aniquila qualquer chance de restabelecê-lo socialmente, por meio do mercado lícito.

A política repressiva usualmente adotada favorece o controle sobre determinados seguimentos sociais, já que, a pretexto de proteger a saúde pública, sempre camufla o interesse econômico do comércio da substância. Não é por acaso que várias outras substâncias que poderiam ser incluídas no conceito de drogas, em razão dos efeitos deletérios que causam à saúde, não foram selecionadas como proibidas, a exemplo do tabaco e do álcool.

A quantidade de vidas desperdiçadas pelo tráfico de drogas e o dispêndio financeiro com a política de repressão e combate revelam que o sistema penal não tem se mostrado eficiente para resolver o problema, tampouco a Lei $n^{\circ}$ I I .343, de 2006, tem atingido o propósito de proteger o bem jurídico a que se propõe, qual seja, saúde pública, o que permite concluir que o Direito Penal não está sendo utilizado como ultima ratio para resolver o problema como deveria, e se o Direito Penal no Estado Democrático de Direito visa limitar o poder punitivo estatal e a sua utilização fora dos princípios constitucionais que o estrutura acaba por estabelecer punições desnecessárias, com nítida violação dos direitos humanos. 
Ante todo esse mosaico, entende-se que a despeito da necessidade de se combater o tráfico, a política de repressão deve ceder espaço para a política de prevenção, de educação e recuperação dos viciados, a fim de reduzir os danos ocasionados pelo vício e principalmente reinserir na sociedade o usuário e o próprio traficante, devolvendo-lhes a dignidade e a cidadania, já que o consumo de drogas é uma realidade que esteve e está presente em todas as sociedades.

\section{REFERÊNCIAS}

BACELLAR, Roberto Portugal. Mudança de cultura jurídica sobre drogas. In: DUARTE, Paulina do Carmo A. Vieira; ANDRADE, Arthur Guerra de (Orgs.). Integração de competências no desempenho da atividade judiciária com usuários e dependentes de drogas. Brasília: Ministério da Justiça, Secretaria Nacional de Políticas sobre Drogas, 2015 .

BARATTA, Alessandro. Criminologia Crítica e Crítica do Direito Penal: introdução à sociologia do direito penal. Tradução de Juarez Girino dos Santos. 3. ed. Rio de Janeiro:Renavan, 2002.

Becker, Howard S. Outsiders: estudos de sociologia do desvio. Rio de Janeiro: Zahar, 2008.

CARVALHO, Salo de. A Política Criminal de Drogas no Brasil: Estudo Criminológico e Dogmático. 4. ed. Rio de Janeiro: Lumen Juris, 2007.

DE GIORGI, Alessandro. A miséria governada através do sistema penal. Rio de Janeiro, Revan, 2006.

GRECO, Rogério. Curso de Direito Penal - Parte Geral. Vol. I. I7. ed. Niterói, RJ: Impetus, 2015.

MASSON, Cleber. Direito Penal Esquematizado. Vol. I. Parte Geral. 8. ed. São Paulo:Método, 2014.

MINISTÉRIO DA JUSTIÇA. Levantamento Nacional de Informações Penitenciárias: Infopen - Dezembro de 20|4. Disponível em: http://www.justica.gov.br/seusdireitos/politica-penal/documentos/infopen_dez|4.pdf.

SOBREIRAS, Henrique Ferro. Manual do criminalista. 4. ed. São Paulo: Tradebook, 2010. 
ZAFFARONI, Eugênio Raúl. O Inimigo no Direito Penal. 2. ed. Rio de Janeiro: Revan, 2007.

ZAFFARONI, Eugênio Raúl; PIERANGELI, José Henrique. Manual de Direito Penal Brasileiro, Vol I. 9. ed. São Paulo: Revista dos Tribunais, 2001.

ZEHR, Howard. Justiça restaurativa. Iª ed. São Paulo: Palas Athena, 2012.

Recebido em: 07/06/2017

Aprovado em: 19/12/2017 